\title{
Historia y Filosofía de la Odontología.
}

History and Philosophy of Dentistry.

Beltrán-Neira RJ. ${ }^{1, a}$

La Odontología es una profesión singular en el concierto de las ciencias de la salud y en la Salud Pública.

En filosofía, identidad es la relación que toda entidad mantiene solo consigo misma.

Es así como la Odontología solo puede ser ella misma y no otra cosa. Es decir posee IDENTIDAD

La atención de las enfermedades de la boca se remonta a épocas pre-históricas.

En las distintas civilizaciones aparece la persona dedicada al cuidado de las enfermedades de la boca.

Antes de la edad contemporánea los sacamuelas y sangradores solían ejercer su oficio en público.

En el siglo XIX se crea la primera escuela dental como institución universitaria. A partir de entonces la educación y la práctica de la odontología avanza aceleradamente. La atención de las enfermedades de la boca se remonta a épocas pre-históricas.

En las distintas civilizaciones aparece la persona dedicada al cuidado de las enfermedades de la boca.

Antes de la edad contemporánea los sacamuelas y sangradores solían ejercer su oficio en público.

En el siglo XIX se crea la primera escuela dental como institución universitaria. A partir de entonces la educación y la práctica de la odontología avanza aceleradamente.

Hitos trascendentales en la historia de la odontología que han contribuido a forjar su identidad :

El primer tratado de Odontologia por Pierre Fouchard

La fundación de la primera escuela universitaria de educación dental.

La aplicación de la anestesia general por los dentistas Wells y Morton.

1 Facultad de Estomatología. Universidad Peruana Cayetano Heredia. Lima, Perú.

a Profesor Emérito. Profesor extraordinario investigador. 
La aplicación de la anestesia local

La utilización de los Rayos X

La aplicación de los fluoruros.

La creación de los departamentos de Odontologia socia

La invención de la turbina dental. Los implantes osteointegrados.

La historia de la Odontología es la base de su identidad como profesión independiente.

Profesión independiente y altruista, como lo demuestran las investigaciones realizadas para prevenir la caries dental mediante la utilización del Flúor y el afán por llevar atención a las poblaciones más necesitadas.

Para caracterizar la identidad de la Odontología es preciso considerar la anatomía, la fisiología y la patología de la boca, sus relaciones sistémicas y sociales, y establecer que la boca no es un órgano, sino un sistema que está constituido por sus órganos: los dientes de la primera y segunda dentición, las glándulas salivares, la lengua y la articulación témporo mandibular; esta entidad también es conocida como sistema masticatorio.

Funciones de la boca.

La boca es el sistema del cuerpo humano que cumple el mayor número de funciones.

Función digestiva

Función respiratoria

Función fonética

Función estética

Función erótico-sexual

Función gestual

Función defensiva

Clases y características singulares de la salud-enfermedad bucal

Enfermedades prevalentes prevenibles.

Patología propia de la boca.

Patología común a otros sistemas.

Repercusión local de problemas sistémicos.

Repercusión sistémica de la patología bucal.

Repercusión de estados fisiológicos.

Traumatismos.

Patología propia.

Aquella patología que se da exclusivamente en la boca:

Caries dental

Enfermedad gíngivo periodontal

Complicaciones infecciosas de la caries dental y de la enfermedad gíngivoperiodontal.

Alteraciones morfológicas y de número de las piezas dentarias.

Mal oclusiones.

Patología de la erupción dentaria.

Tumores de los maxilares originados en tejido dentario.

Patología común a otros sistemas.

Cáncer y lesiones pre cancerosas.

Otros tumores benignos y malignos

Metástasis en los maxilares.

Manifestaciones bucales de enfermedades sistémicas 
Manifestaciones bucales de procesos fisiológicos.

Traumas.

Educación.

Facultades, escuelas y departamentos autónomos.

Maestrías, doctorados, especializaciones.

Currículos propios.

Aprendizaje clínico original.

Trabajo de campo innovador.

Forma de graduación independiente.

Vinculación con carreras técnicas y auxiliares para la formación de equipos de salud bucal

Formas de práctica profesional

Práctica individual independiente.

Práctica en equipo.

Práctica institucional privada.

Práctica institucional pública.

Docencia.

Investigación.

Peritaje.

Organizaciones profesionales propias

Colegios profesionales y asociaciones nacionales.

Sindicatos y Federaciones profesionales.

Academias.

Asociaciones de especialidades.

Organizaciones Internacionales y mundiales.

Ubicación mundial

La Odontología tiene un lugar particular en el organismo de las Naciones Unidas, la Organización Mundial de la Salud y su Oficina Regional para las Américas, la Organización Panamericana de la Salud. En cada una de ellas tiene un oficial odontólogo responsable.

La Federación Dental Internacional (FDI), es la organización profesional internacional más antigua del mundo, se fundó en Francia el año 1900 con ocasión de la Feria Mundial, por iniciativa del odontólogo francés Charles Godon.

La FDI celebra anualmente congresos internacionales en diferentes capitales del mundo en asociación con la institución odontológica del respectivo país.

Congresos y jornadas.

La profesión realiza periódicamente congresos, jornadas y otras formas de intercambio, incluyendo las conferencias vía Internet.

Por el número de concurrentes se destacan, los congresos de FDI, de Sao Paulo, de la International Association of Dental Research y de la American Dental Association. El primer congreso mundial de educación odontológica se realizó en Praga en el año 2001.

Especialidades de la Odontología.

La amplitud y variedad de los problemas de la salud bucal

ha demandado el desarrollo de especialidades: 
Odontología pediátrica.

Medicina y patología bucal

Cirugía bucal y maxilofacial.

Salud Pública

Periodoncia

Endodoncia

Rehabilitación

Toda persona, institución o profesión tiene la potestad de establecer y proteger su IDENTIDAD.

La Odontología se define como una profesión de servicio social en el campo de la salud bucal.

A su vez, la práctica odontológica se conceptualiza como la respuesta científica, técnica, social y ética de la odontología a las necesidades y prioridades de salud bucal de la población en un contexto determinado.

En salud pública la odontologia aporta el resultado de sus investigaciones y experiencias para la ampliación de los servicios públicos, la extensión de la cobertura, la promoción de la salud y la prevención de la enfermedad.

La Odontología es una profesión con identidad propia, independencia en su ejercicio y capacidad para el trabajo inter y transdisciplinario en el campo de la salud.

El orgullo de ser odontólogo se sustenta en la nobleza de la profesión. Porsu entrega al servicio de la salud y bienestar físico, psíquico y social en procura del mejoramiento de la calidad de vida de la humanidad.

Sin embargo, debemos reconocer que la odontología tiene una deuda social pendiente, porque no ha cumplido plenamente con su función preventiva.

La promoción de la salud bucal y la prevención de las enfermedades de la boca son el gran reto del siglo XXI.

\section{CORRESPONDENCIA}

Prof. Roberto J. Beltrán

robertobeltranneira@gmail.com

Recibido : 13-01-2013

Aceptado: 10-04-2013 